\title{
CORRESPONDENCE
}

\section{Prothrombotic phenotype in COVID-19 severe patients}

\author{
Julie Helms ${ }^{1,2}$, François Severac ${ }^{3}$, Hamid Merdji ${ }^{1,4}$, Eduardo Anglés-Cano ${ }^{5}$ and Ferhat Meziani ${ }^{1,4^{*}}$ (1)
}

(c) 2020 Springer-Verlag GmbH Germany, part of Springer Nature

\section{Dear Editor,}

We thank Rech TH and co-workers [1] for their interest in our study [2]. The incidence of pulmonary embolism $(\mathrm{PE})$ in patients with SARS-CoV-2 may be influenced by the number of CT pulmonary angiography (CTPA) performed when PE is suspected.

In our study, CTPA was performed in a population in which we were looking for a cause to clinical deterioration, which might be due to PE, but also to mechanical ventilation-acquired pneumonia. We therefore did not necessarily select a population with a strong suspicion of PE. We did not have a systematic standardized assessment of thromboembolic events as well. Imaging was thus performed based on the evolution of clinical or laboratory parameters. Respiratory $\left(\mathrm{PaO}_{2} / \mathrm{FiO}_{2}\right)$ or hemodynamic deterioration, or evidence of dilated right ventricle-even without acute cor pulmonalewas explored by CTPA. A rapid elevation of D-dimer despite anticoagulation, reflecting increased thrombin generation, i.e., clot formation, and fibrinolysis, was investigated. D-dimer level did not differ at baseline between patients with/without pulmonary embolism, but increased with thrombotic events during ICU stay, with D-dimers $>5 \mathrm{mg} / \mathrm{L}$ in $92 \%$ of the patients. A sudden increase in D-dimer level along with clinical deterioration was an additional argument to explore patients by CTPA.

The number of CTPA performed in our study to detect $\mathrm{PE}$ is indeed rather high. However, bed chest X-ray was time-consuming and of poor interest in COVID-19

\footnotetext{
*Correspondence: Ferhat.Meziani@chru-strasbourg.fr

${ }^{1}$ Hôpitaux Universitaires de Strasbourg, Service de Médecine Intensive Réanimation, Nouvel Hôpital Civil, 1, place de l'Hôpital, 67091 Strasbourg cedex, France

Full author information is available at the end of the article
}

wards. Lung ultrasonography was thus routinely used to detect condensation or pleural effusion. We decided to perform CT-scan to (re)explore patients when ultrasonography alone could not explain blood gas deterioration. In the historical cohort of non-COVID-19 ARDS, 168 CT-scans were performed in 134 patients during their ICU stay, among which 65 were CTPA. The incidence of PE found was of $4.6 \%$ in the non-COVID ARDS cohort compared to $25 \%$ in the present COVID-19 cohort. We had the same clinical/biological arguments to ask for a CTPA in the historical cohort. Yet, only $28 \%$ of the patients required CTPA, which may have led to a potential bias of an increased detection of PE in COVID19 patients. Finally, even if we exclude subsegmentary PE, the difference between COVID-19 and non-COVID ARDS remains statistically significant (3/233 patients, $1.3 \%$, versus $22 / 150$ patients, $14.7 \%, \mathrm{p}<0.001)$.

Our study reports a high rate of PE, in line with other studies published concomitantly. In 184 ICU patients with proven COVID-19 pneumonia, Klok et al. [3] showed that the cumulative incidence of the composite outcome including venous thromboembolism and arterial thrombotic complications was 31\% (95\%CI 20-41\%) and that CTPA-diagnosed PE was the most frequent thrombotic complication $(\mathrm{n}=25,81 \%)$. Poissy et al. reported that 22/107 COVID-19 patients (20.6\%) admitted in ICU were diagnosed with PE, with an absolute increase risk of $14.4 \%$ (95\% CI 6.1 to $22.8 \%$ ) compared to patients hospitalized in the same ICU during the same time interval in 2019 (20.6\% vs 6.1\%; absolute increase risk of $14.4 \%, 95 \% \mathrm{CI} 6.1$ to $22.8 \%$ ) [4]. In a smaller cohort, Llitjos et al. [5] reported $6 \mathrm{PE}$ in 26 patients (23\%) (4 CTPA and 2 transesophageal echocardiography diagnosis). These studies are, however, difficult to compare, because the incidence of PE reported may depend on the number of CTPA performed on the global cohort.

\section{Springer}


Although PE is a major thromboembolic complication in ICU, no study has systematically assessed the incidence or prevalence of this complication in ICU COVID-19 patients. Systematic CTPA screening of all patients irrespective of symptoms is the only way to assess the incidence of PE. Despite a number of limitations, our study has the strengths of being multicenter and prospective, and reporting for the first time a large number of patients. Our results are of pressing importance to better understand peculiarities of the many patients currently treated during the ongoing COVID19 crisis worldwide. Potentially practice changes may be envisaged in terms of anticoagulation, coagulopathy profile and systematic assessment of venous thromboembolism.

\footnotetext{
Author details

${ }^{1}$ Hôpitaux Universitaires de Strasbourg, Service de Médecine Intensive Réanimation, Nouvel Hôpital Civil, 1, place de l'Hôpital, 67091 Strasbourg cedex, France. ${ }^{2}$ ImmunoRhumatologie Moléculaire, INSERM UMR_S1109, LabEx TRANSPLANTEX, Centre de Recherche d'Immunologie et d'Hématologie, Faculté de Médecine, Fédération Hospitalo-Universitaire (FHU) OMICARE, Fédération de Médecine Translationnelle de Strasbourg (FMTS), Université de Strasbourg (UNISTRA), Strasbourg, France. ${ }^{3}$ Hôpitaux Universitaires de Strasbourg, Groupe Méthodes en Recherche Clinique (GMRC), Hôpital Civil, Strasbourg, France. ${ }^{4}$ INSERM (French National Institute of Health and Medical Research), UMR 1260, Regenerative Nanomedicine (RNM), FMTS, Strasbourg, France. ${ }^{5}$ Université de Paris, Innovative Therapies in Haemostasis, INSERM UMR S 1140, 75006 Paris, France.
}

\section{Compliance with ethical standards}

Conflict of interest

The authors declare that they have no conflict of interest.

\section{Publisher's Note}

Springer Nature remains neutral with regard to jurisdictional claims in published maps and institutional affiliations.

Accepted: 30 April 2020

Published online: 20 May 2020

\section{References}

1. Rech TH et al (2020) Incidence of pulmonary embolism in patients with COVID-19. Intensive Care Med (In Press)

2. Helms J, Tacquard C, Severac F, Leonard-Lorant I, Ohana M, Delabranche X, Merdji H, Clere-Jehl R, Schenck M, Fagot Gandet F, Fafi-Kremer S, Castelain V, Schneider F, Grunebaum L, Anglés-Cano E, Sattler L, Mertes PM, Meziani $F$ (2020) High risk of thrombosis in patients in severe SARS-CoV-2 infection: a multicenter prospective cohort study. Intensive Care Med. https://doi.org/10.1007/s00134-020-06062-x

3. Klok FA, Kruip M, van der Meer NJM, Arbous MS, Gommers D, Kant KM, Kaptein FHJ, van Paassen J, Stals MAM, Huisman MV, Endeman H (2020) Incidence of thrombotic complications in critically ill ICU patients with COVID-19. Thromb Res. https://doi.org/10.1016/j.thromres.2020.04.013

4. Poissy J, Goutay J, Caplan M, Parmentier E, Duburcq T, Lassalle F, Jeanpierre E, Rauch A, Labreuche J, Susen S, Lille ICUHC-g, (2020) Pulmonary embolism in COVID-19 patients: awareness of an increased prevalence. Circulation. https://doi.org/10.1161/CIRCULATIONAHA.120.047430

5. Llitjos JF, Leclerc M, Chochois C, Monsallier JM, Ramakers M, Auvray M, Merouani K (2020) High incidence of venous thromboembolic events in anticoagulated severe COVID-19 patients. J Thromb Haemost. https://doi. org/10.1111/jth.14869 